\begin{tabular}{|c|c|c|c|c|c|c|}
\hline $\begin{array}{l}\text { Burden to } \\
\text { others }\end{array}$ & $60,4 \pm 27,2$ & $\begin{array}{c}39,5 \\
\pm 23,1\end{array}$ & $<0,0001$ & $57,7 \pm 27,3$ & $42 \pm 29,9$ & 0,001 \\
\hline $\begin{array}{l}\text { Emotion } \\
\text { health }\end{array}$ & $70,8 \pm 21,2$ & $37,9 \pm 22$ & $<0,0001$ & $66,6 \pm 24,2$ & $40,1 \pm 20,3$ & $<0,0001$ \\
\hline Body image & $69,8 \pm 25,7$ & $48 \pm 27,6$ & $<0,0001$ & $67 \pm 26,8$ & $45,7 \pm 28,6$ & 0,001 \\
\hline Fatique & $67,9 \pm 22,4$ & $40 \pm 22,4$ & $<0,0001$ & $64,4 \pm 24,3$ & $41 \pm 21,7$ & $<0,0001$ \\
\hline
\end{tabular}

Disclosure of Interests: None declared

DOI: 10.1136/annrheumdis-2019-eular.4523

\section{AB0569 THE EFFECT OF CUTANEOUS AND MUSCULOSKELETAL SYMPTOMS ON QUALITY OF LIFE IN PATIENT WITH SYSTEMIC LUPUS ERYTHEMATOSUS IN RENAISSANCE COHORT}

Lyubov Vorobyova, Elena Aseeva, Sergey Solovyev. V.A.Nasonova Research Institute of Rheumatology, Intensive care department, Moscow, Russian Federation

Background: Cutaneous and musculoskeletal symptoms is one of the most frequent clinical complaints of patients with systemic lupus erythematosus(SLE) and has been found to occur in up to $70 \%-95 \%$ of patients during the course of the disease. For these reasons, SLE can affect different aspects of the patient's life, leading to an impairment of HRQOL.

Objectives: The aim of the current study was to assess the effect of cutaneous and musculoskeletal symptoms on HRQoL in a cohort of patients with systemic lupus erythematosus in Russian Federation (RENAISSANCE).

Methods: Consecutive patients who fulfilled SLICC 2012 criteria for SLE were recruited. Health-related quality of life (HRQoL) was assessed by the validated specific questionnaires LupusQoL-Russian. Disease activity was evaluated by the SLEDAI-2K, and chronic damage by the Systemic Lupus International Collaborating Clinics Damage Index score (SDI).

Results: 328 Russian SLE patients were enrolled in the study (M/F 30/ 298, mean age $34.4 \pm 11.5$ years, mean disease duration $106.3 \pm 97.9$ months; mean SLEDAI $2 \mathrm{~K}$ 9.6 \pm 8.0 ; mean SDI $0.2 \pm 0.6$. Musculoskeletal symptoms were observed in 142 patients, cutaneous and mucosal lesion symptoms -147 patients, respectively. When comparing HRQOL in patients with lesions skin and mucousal revealed (Table 1) significant decline HRQoL on the scales "Planning" (58.5 \pm 28.9), "Intimate Relationships" (65.9 \pm 32.1), "Burden to other" (52.9 \pm 26$)$ and "Body Image" (57.4 \pm 29.1) of the LupusQol questionnaire compared with the patients without skin and mucosal lesions $(p \leq 0.002 ; p \leq 0.001 ; p \leq 0.03 ; p \leq 0,0001$ respectively). When evaluating HRQoL in patients with SLE and musculoskeletal symptoms (Table 2) reduction of almost all scales LupusQoL.

Conclusion: Cutaneous and musculoskeletal symptoms in SLE patients were associated with significantly poorer HRQoL.

Table 1. Dependence of indicators of the scales of the LupusQol on the presence of the skin and mucosal lesions $(\mathrm{p}<0.05)$.

\begin{tabular}{lccc}
\hline LupusQoL & $\begin{array}{c}\text { No involved skin and mucosal } \\
\text { lesions }(\mathbf{N}=\mathbf{1 8 1})\end{array}$ & $\begin{array}{c}\text { Involved skin and } \\
\text { mucosals lesions } \\
\mathbf{( N = 1 4 7 )}\end{array}$ & $\mathbf{P}$ \\
\hline $\begin{array}{l}\text { Physical } \\
\text { health }\end{array}$ & $68,03 \pm 23$ & $65,03 \pm 23,5$ & 0,2 \\
Pain & $66,2 \pm 26,7$ & $62,6 \pm 21,8$ & 0,2 \\
Planning & $72,19 \pm 25$ & $67,2 \pm 24$ & 0,07 \\
Intimate & $64 \pm 24,6$ & $61 \pm 24,8$ & 0,3 \\
relationship & $68,1 \pm 27,4$ & $58,5 \pm 28,9$ & 0,002 \\
$\begin{array}{l}\text { Burden to } \\
\text { others }\end{array}$ & $78,4 \pm 29$ & $65,9 \pm 32$ & 0,001 \\
$\begin{array}{l}\text { Emotion } \\
\text { health }\end{array}$ & $59,5 \pm 29$ & $52,9 \pm 26$ & 0,03 \\
Body image & $71,7 \pm 24$ & $57,4 \pm 29$ & $<0,0001$ \\
Fatigue & & & \\
\hline
\end{tabular}

Table 2. The dependence of the indicators of the questionnaire scales LupusQoL from musculoskeletal symptoms $(p<0.05)$.

\begin{tabular}{lccc}
\hline LupusQoL & $\begin{array}{c}\text { No musculoskeletal } \\
\text { symptoms (N=186) }\end{array}$ & $\begin{array}{c}\text { musculoskeletal symptoms } \\
(\mathbf{N}=\mathbf{1 4 2})\end{array}$ & $\mathbf{p}$ \\
\hline Physical health & $69,6 \pm 23$ & $62,8 \pm 22,6$ & 0,008 \\
Pain & $67,2 \pm 28$ & $62,8 \pm 22,6$ & 0,1 \\
Planning & $74,5 \pm 24$ & $64 \pm 23,7$ & 0,001 \\
Intimate & $45,9 \pm 7,6$ & $44 \pm 7,5$ & 0,04 \\
relationship & & &
\end{tabular}

\begin{tabular}{llll}
$\begin{array}{l}\text { Burden to } \\
\text { others }\end{array}$ & $68 \pm 28,4$ & $58,3 \pm 27$ & 0,02 \\
Emotion health & $77 \pm 29,9$ & $67,2 \pm 31$ & 0,01 \\
Body image & $58,6 \pm 27$ & $54 \pm 28,6$ & 0,02 \\
Fatigue & $65,2 \pm 25$ & $59,3 \pm 23$ & 0,03 \\
\hline
\end{tabular}

Disclosure of Interests: None declared

DOI: 10.1136/annrheumdis-2019-eular.4520

\section{AB0570 CLINICAL STUDY OF THE DISEASE ACTIVITY AND IMMUNE SCREENING OF PRIMARY SJOGREN'S SYNDROME}

Yin Xufang, Zhang Mingxing, Ming Yan, LI Xiao-Feng. The Second Hospital of Shanxi Medical University, Taiyuan, China Objectives: To evaluate the change features of peripheral blood lymphocyte subsets and disease activity in patients with primary Sjogren's syndrome before and after treatment.

Methods: A total of 30 patients with primary Sjogren's syndrome in the Department of Rheumatology from the Second Hospital of Shanxi Medical University from January 2016 to December 2018 were enrolled. According to the treatment time of patients, they were divided into baseline group, 0-3 months group, 3-6 months group, 6-12 months group, and the absolute counts of $\mathrm{T}, \mathrm{B}, \mathrm{NK}$, Th1, Th2, Th17 and regulatory $\mathrm{T}$ cells(Tregs) in peripheral blood of patients before and during the treatment were measured by flow cytometry. The ratio of various cells to Tregs was calculated as well.The primary Sjogren's syndrome disease activity was assessed according to the Sjögren's syndrome disease activity index (ESSDAI) score and compared with 30 healthy people.

Results: The Tregs counts in the disease group were significantly lower than those in the healthy control group $(p<0.05)$, and the ratio of proinflammatory lymphocytes to Tregs (Th17/Treg) was higher $(p<0.05)$. Tregs counts in peripheral blood of patients with primary Sjogren's syndrome has increased significantly after 3-month treatment,at the same time, the inflammatory index ESR was significantly lower $(p<0.05)$, the ESSDAI score was significantly lower $(p<0.05)$, and the high remission rate was maintained. However there was no statistically significant increase in Treg cell growth before treatment at 3-6 months and 6-12 months, $(p>0.05)$.
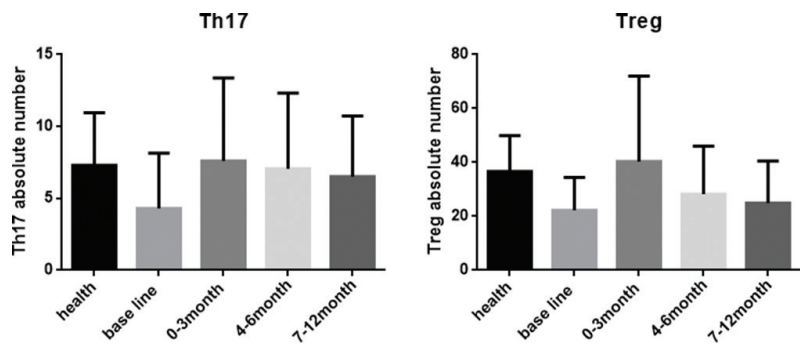

Figure 1The. Tregs counts in the disease group were significantly lower than those in the healthy control group $(p<0.05)$, and the ratio of proinflammatory lymphocytes to Tregs (Th17/Treg) was higher $(p<0.05)$.Tregs counts in peripheral blood of patients with primary Sjogren's syndrome has increased significantly after 3-month treatment.
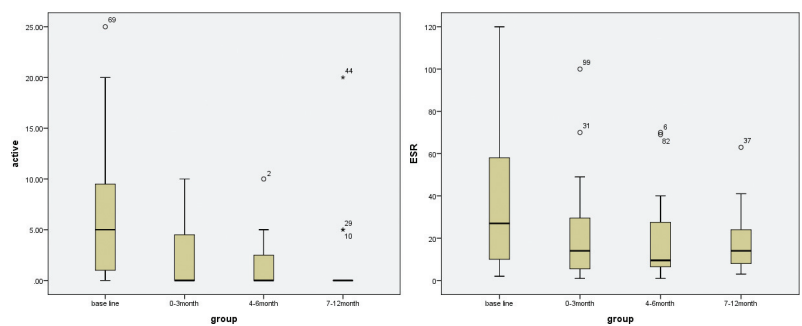

Figure 2the. inflammatory index ESR was significantly lower $(p<0.05)$, the ESSDAI score was significantly lower $(p<0.05)$, and the high remission rate was maintained.

Conclusion: The imbalance between pro-inflammatory lymphocytes and Tregs caused by the significant decrease of Tregs may be the cause of primary Sjogren's disease activity. We propose to promote the growth of Tregs and maintain the balance between pro-inflammatory lymphocytes and Tregs,which provides a new idea for disease relief of primary Sjogren's syndrome. 